\title{
Developing theory-driven design research
}

\section{Cash, Philip J.}

\section{Published in:}

Design Studies

Link to article, DOI:

10.1016/j.destud.2018.03.002

Publication date:

2018

\section{Document Version}

Peer reviewed version

Link back to DTU Orbit

Citation (APA):

Cash, P. J. (2018). Developing theory-driven design research. Design Studies, 56, 84-119.

https://doi.org/10.1016/j.destud.2018.03.002

\section{General rights}

Copyright and moral rights for the publications made accessible in the public portal are retained by the authors and/or other copyright owners and it is a condition of accessing publications that users recognise and abide by the legal requirements associated with these rights.

- Users may download and print one copy of any publication from the public portal for the purpose of private study or research.

- You may not further distribute the material or use it for any profit-making activity or commercial gain

- You may freely distribute the URL identifying the publication in the public portal

If you believe that this document breaches copyright please contact us providing details, and we will remove access to the work immediately and investigate your claim. 


\section{Developing theory-driven design research}

Philip J. Cash, Department of Management Engineering, Section of Engineering Design and Product Development, Technical University of Denmark, Produktionstorvet, DK-2800 Lyngby, Denmark

Design research is increasingly weak in comparison with other fields; without action to increase scientific, theoretical, and methodological rigour there is a real possibility of the field being superseded and becoming obsolete through lack of impact. The aim of this paper is to show how design research could become more rigorous, relevant and have greater impact. I conduct a two-part review that combines systematic and critical components. Part one characterises the major scientific challenges facing design research, and part two examines how such challenges have been addressed in related fields. I identify key learning indicating future directions for theory-driven design research. I conclude by providing some concrete recommendations for the field of design research and individual design researchers.

(C) 2018 Elsevier Ltd. All rights reserved.

Keywords: research methods, design research, design science, research theory

Corresponding author: Philip J. Cash pcas@dtu.dk

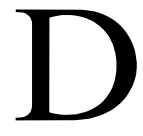
esign research ranges from descriptive examinations of design in context, to prescriptive propositions for how design should be (Blessing \& Chakrabarti, 2009, p. 15), and from the individual to the organisational level (McMahon, 2012, p. 570). To address research questions along this spectrum design researchers have drawn on a series of findings and methods from related fields (Cash, Skec, \& Storga, 2013, p. 45; McMahon, 2012, p. 565). These fields overlap with design research in relation to subject, methods, or theory, however, design researchers face a number of specific scientific challenges. Increased rigour is needed to avoid stagnation, low impact and potential obsolescence. Design research risks being superseded by other fields eager to include design science in their portfolios.

The need for action is clear. Design researchers are finding it increasingly difficult to claim that examinations of design phenomena constitute a unique contribution. For example, management researchers are exploiting opportunities to adopt design as another managed process. The Journal of Product Innovation Management (JPIM) (a highly ranked management journal) has begun to include design as part of its portfolio, with special issues including 'Product design research and practice' in 2011, and 'Co-creation with customers' in 2017. Similarly, the Journal of Operations Management (JOM) has created its own 'Design Science' track, and Thinking \& Reasoning has explored many topics that underpin design research, for example, its 2015 special issue 
on 'Creativity and insight problem solving' (Sowden, Pringle, \& Gabora, 2015). Thus, design research as a unique field is being challenged across the entire descriptive/prescriptive spectrum.

Despite the potential for design research to leverage these parallel developments by providing theory that other researchers could exploit, there is little evidence of that happening. In the 2011 JPIM special issue, the top four general design journals (see Appendix) received a total of 17 citations; in its 2017 special issue they received none. In $J O M$, the top design journals received only one citation between 2010 and 2016. Similarly, the 2015 Thinking \& Reasoning special issue included only eight citations to the top design journals. Generally, the journals in these related fields have a higher Impact Factor (based on the journal listings by Liang et al. (2015) and Gemser, De Bont, Hekkert, and Friedman (2012)) despite representing fields of similar overall size to design research. Contrasting average Impact Factors for the top journals in 2016 is revealing (Average Impact Factor of top four journals in: operations management -3.297 , innovation management -3.491 , applied psychology -7.973 , design - 1.802). Also, researchers publishing in design journals often draw on theories developed in fields such as management or applied psychology. For example, Yu, Honda, Sharqawy, \& Yang (2016) (Design Studies) adopt the theoretical foundation provided by Ball, Evans, Dennis, \& Ormerod (1997) (Thinking \& Reasoning), and van der Bijl-Brouwer and Dorst (2017, p. 36) (Design Studies) use Verganti (2008) (JPIM) as an explicit theoretical counterpoint. However, instances of researchers in these alternative fields using design research theory are rare.

While design researchers draw extensively on related fields, the reverse does not occur. This asymmetrical relationship emerges clearly in relation to the field of innovation management. In 2016, the top four innovation management journals were cited in over $16 \%$ of the papers in the top design journals, but the top design journals were cited in only $2 \%$ of innovation management papers. This disparity is particularly critical since the research questions, methods and associated theories in these examples are very close to those found in design research. In $2016,13 \%$ of the papers in the top four innovation management journals dealt specifically with a 'product design' aspect and almost all were related to some aspect of product development. Common topics included ideation and innovation, idea selection and team interaction, and were studied using a variety of methods familiar to design researchers, such as latent semantic analysis, cases, interviews, experiments and surveys. Some authors, such as Ball and Ormerod (Ball \& Ormerod, 2000a; Ball et al., 1997) and Karjalainen and Snelders (Karjalainen \& Snelders, 2010; Person, Schoormans, Snelders, \& Karjalainen, 2008) publish across design and other fields. However, despite overlaps in the research approach, topic and some authors, the other fields 
are establishing their own 'design' literature, with little or no acknowledgement to relevant work in mainstream design research.

Given the above, it is not feasible for design research to continue to do 'what has always been done'. There have been repeated warnings that design research is facing distinct theoretical (Love, 2002, p. 346), methodological (McMahon, 2012, p. 575), and scientific challenges (Cash, Stankovic, \& Storga, 2016a, p. 5) that are affecting its impact and relevance. These warnings cannot go unheeded if the field of design research is to survive. The time to act is now because the growing interest in design across these related fields is offering a potential springboard for revitalising the impact of design research. Although the challenges facing design research are distinct, we can draw clear parallels to other fields. For example, research in medicine (Sackett, Rosenberg, Gray, Haynes, \& Richardson, 1996), psychology (Wilkinson, 1999), management (Melnyk \& Handfield, 1998) and education (Levin \& O'Donnell, 1999) has explicitly highlighted and sought to overcome similar challenges. In each of these cases, researchers have contrasted internal critique to insights from related fields to identify the challenges and formulate recommendations. I adopt a similar model in this paper.

To begin this critique, I highlight theory-driven research as a basis for understanding the responses to scientific challenges across fields. Theory-driven research allows the abstraction of knowledge from the specifics of context, field and subject, and its formulation into theory (Briggs, 2006; Eisenhardt \& Graebner, 2007; Friedman, 2003). A theory is the explanation of a set of conceptual relationships in which concepts, constructs and principles are defined; the application domain is explicit; how and why relationships exist is explained; and what could, should and would happen in a range of circumstances is predicted (Wacker, 2008, p. 7). A model or other description lacking any one of these properties is not a theory (Dubin, 1978; Wacker, 2008, p. 7). Reflection on theory-driven research was the trigger for many of the major scientific critiques and developments in psychology (Maxwell, Lau, \& Howard, 2015; Reiser, 1939) and education (Levin \& O’Donnell, 1999). It also underpinned the transformation of operations management from an applied to a more widely cited and scientifically robust field (Melnyk \& Handfield, 1998) and underlies much of the soul-searching in current general management research (Honig, Lampel, Siegel, \& Drnevich, 2017). Thus, I ground my examination of design research and comparison with related fields on this foundation.

I will address the question of how design research might be steered towards greater rigour, relevance and impact. The aim is not to prescribe how researchers should do their work or to diminish the undeniable value of prior design research. Rather, I want to show how stronger theory-driven research could cohere and transform design research. To do this I conduct a mixed 
methods analysis which combines systematic and critical reviews (Grant \& Booth 2009, p. 94) of the design and related fields. The systematic elements are based on the work of Higgins, Green, \& Collaboration (2008) and focus on 'general design research' as defined by Gemser et al. (2012, p. 12). I review recent publications (2010-2016) in major design journals, following prior work in this vein (Cash et al., 2013; Chai \& Xiao, 2012). The limitation to this method is that the extent of specific features in the literature may be over/under-estimated in the summary statistics. Therefore, the results are developed and contextualized using comparative critical review of design and the related fields. This allows systematic identification of the literature and reflection on the general validity of the findings (see Appendix).

The paper is structured as follows. Section 1 identifies common foundations of theory-driven research. Section 2 identifies the difficulties confronting current design research. Section 3 identifies the lessons that can be learned from contrasting design research with related fields that have faced similar challenges. The paper concludes with recommendations related to fostering more robust, theory-driven design research.

\section{Theory-driven research}

Theory-driven research is at the core of robust scientific knowledge. This connects three symbiotic components: theory building, research methods and the body of scientific knowledge (Briggs, 2006; Eisenhardt \& Graebner, 2007; Kitchenham et al., 2002). 'Good' theory-driven research allows researchers to build a corpus of robust scientific knowledge that is valuable internally and accessible externally. Thus, theory-driven research provides a foundation for understanding research challenges across fields.

\subsection{The theory building/testing cycle}

Theory-driven research is underpinned by a theory building/testing cycle, involving a process of exploration, theory creation and systematisation, and empirical scrutiny and refinement. This cycle comprises a number of fundamental steps (Eisenhardt, 1989, p. 533; Gorard \& Cook, 2007, p. 319; Handfield \& Melnyk, 1998, p. 324; Hevner, 2007, p. 88) that describe how theory-driven research cyclically shapes a body of scientific knowledge that captures the field's understanding of its subject. If the cycle breaks down, the build-up of scientific understanding is halted and research stagnates.

Given the importance of the theory building/testing cycle, I first clarify the generally accepted steps and associated research questions. This allows the specification of methods based on the type of research questions asked and the nature of the theory under investigation (Gorard \& Cook, 2007, p. 321). This is particularly important for understanding how both qualitative and quantitative methods can be useful for addressing research questions along 
the descriptive/prescriptive spectrum (Flyvbjerg, 2006; Levin \& O'Donnell, 1999). For example, traditionally, Randomised Controlled Trials (RCTs) are associated to testing generalizable causal claims relevant to whole populations or systems, for example, medical interventions (Grimes \& Schulz, 2002, p. 57), or design interventions to improve creativity (King \& Sivaloganathan, 1999, p. 332). However, theoretical claims can also be highly contextualised. Here, testing might be supported better by case-based methods, for example, examination of extreme cases or identification of situations where propositions are falsified (Clay, 2010, p. 52; Flyvbjerg, 2006, p. 11). It is the combination of methods that supports the most robust theory and scientific knowledge developments (Shah \& Corley, 2006, p. 1831). Thus, all methods could be useful in all steps, but can be critically assessed with respect to the type of research question and the related theory.

For each step, I summarise the main aims, the research questions and types of methods used, and provide an illustration of the overall process by following a stream of the design research literature. Figure 1 shows that the researcher can enter the cycle at any point and by 'spiralling' through it can build up scientific knowledge (Carroll \& Swatman, 2000, p. 240; Meredith, 1993, p. 4).

Discovery and description (theory building mode): identifying areas of interest and important issues; asking questions that establish the general characteristics of what is going on in a situation, the key issues and the potential importance of research in this area, supported by methods targeting in depth understanding. For example, Fish and Scrivener's (1990) description of sketching as important in representational cognition.

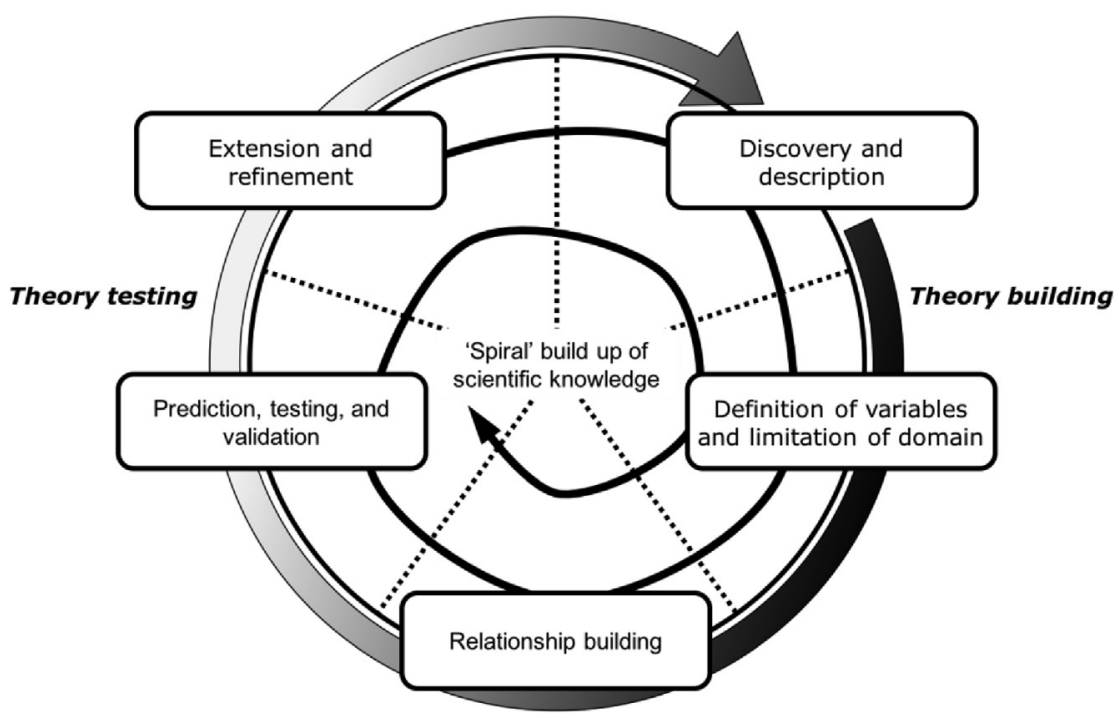

Figure 1 The theory building/testing cycle showing the 'spiral' build up of scientific knowledge 
Definition of variables and limitation of domain (theory building mode): identifying variables and mapping interconnections and boundaries; asking questions to identify the key variables and identify salient themes, patterns and categories, supported by methods aimed at broadening our understanding. For example, Kavakli, Scrivener and Ball's (1998) exploratory experiment which frames the progression of representational sketching as a crucial variable for design.

Relationship building (theory building mode): describing connections between variables and the underpinning mechanisms that explain the 'why' of these connections; asking questions that establish relationships among the variables whether it is possible to identify an order in these relationships or explain why such relationships should exist, supported by methods to describe the specific relationships between variables. For example, Scrivener et al.'s (2000) reanalysis of Kavakli's (1998) study identifies a distinct relationship between representational sketching and uncertainty perception.

Prediction, testing and validation (theory testing mode): testing the theoretical model emerging from the previous step and predicting future outcomes; posing validation questions and contrasting empirical results and theoretical explanations/predictions, supported by methods to test propositions, explanations and predictions. For example, Ball et al.'s (2010) preliminary testing, using protocol data, of predictions linking uncertainty perception and the generation of ideas via representational sketching.

Extension and refinement (theory testing mode): expanding and mapping the theoretical model derived from the previous step; posing questions to establish the extent of its power and refine its structure with respect to empirical observations, supported by methods to test applicability, generalisability and scope. For example, Tseng and Ball (2010) extend Scrivener et al.'s (2000) and Ball et al.'s (2010) work by experimentally examining the links between uncertainty perception, interpretation of representational sketches and idea development.

Each of the above steps synthesises theory building, research methods and the body of scientific knowledge. In the context of theory building, each step is associated to aspects of good practice. For example, uniqueness and conservation in theory building mode (i.e., concepts are either connected to or differentiated from standard extant concepts), and predictive power and refutability in theory testing mode (Wacker, 1998, p. 365). In the context of research methods, the steps in this cycle provide the basis for directing the application of all types of methods, from analytical (e.g., conceptual, mathematical, statistical) to empirical (e.g., experimental, statistical, case study) (Robson \& McCartan, 2011, p. 67; Scandura \& Williams, 2000, p. 1262). Finally, in relation to the body of scientific knowledge, each step provides distinct insights that contribute different types of knowledge (e.g., explanatory, predictive, 
causal) (Gregor, 2006, p. 620; Reynolds, 1971, p. 2). Without an understanding of where within this cycle the research fits it is impossible to define the methods best suited to addressing specific research questions or to integrate insights effectively.

\subsection{Symbiosis between theory and method}

Understanding how research contributes to the theory building/testing cycle enables the selection and application of a research method (Amundson, 1998, p. 356), assessment of its success (Gorard \& Cook, 2007, p. 315) and evaluation of the evidence provided (Grimes \& Schulz, 2002, p. 57). Understanding of 'robust' methods cannot be atheoretical. For example, it is common for researchers to argue the relative merits of quantitative verses qualitative methods (Flyvbjerg, 2006; Gorard \& Cook, 2007). However, this assumes one method is generally better than the other. In the theory building/testing cycle, all methods provide distinct contributions in each step, and it is often their combination that provides the richest understanding (Shah \& Corley, 2006). For instance, an experiment might be suited to testing generalised causal claims (Kirk, 2009), but compared to an ethnographic method, would be much less appropriate to test context-specific falsification (Flyvbjerg, 2006). Qualitative and quantitative insights can be combined to produce accurate and clearly-defined theory, and to describe its wider applicability and boundary conditions (Shah \& Corley, 2006, p. 1832). Thus, explicit theoretical framing is essential for the application and evaluation of research methods.

Theory-driven research supports the use of research methods in three main ways: it defines the application of a specific method; it shapes the development of the method; and it provides a basis for examining the rigour of the method. Without an understanding of the underlying theory building/testing cycle, it is almost impossible to develop meaningful application standards, research practice norms or common analytical foundations (Grimes \& Schulz, 2002; Malterud, 2001). In the absence of such common standards, many important qualitative and quantitative research methods will be excluded from the researcher's repertoire. For example, qualitative methods will be robbed of their value. Instead of generating insights that support wider methodological integration and theory development, they will remain contextually disconnected (Flyvbjerg, 2006, p. 221). Case studies have been used in design generally to describe creative leaps in professional practice (Cross, 1997, p. 428), novice sketching (Scrivener et al., 2000, p. 468) and ideation (Gonçalves, Cardoso, $\&$ Badke-Schaub, 2016, p. 23). However, because the underlying mechanisms are not well understood, these insights are difficult to bring together or translate into more generally supportive design tools or interventions (Ozkan \& Dogan, 2013, p. 187). Similarly, without common standards, it is not possible to support key quantitative methods such as meta-analysis (Glass, 1976, p. 3) 
or RCTs (Levin \& O'Donnell, 1999, p. 203). When testing generalizable causal claims, meta-analyses and RCTs provide the strongest possible quantitative evidence (Grimes \& Schulz, 2002, p. 57). Such claims are often made in design with regard to design tools, for example, in terms of generating and selecting the best concepts (King \& Sivaloganathan, 1999). However, without methodological rigour in the understanding of the underlying psychological processes (Daalhuizen, 2014, p. 46), cause-effect results may not materialise in practice (Araujo, Benedetto-Neto, Campello, Segre, \& Wright, 1996). Lack of ability to use these research methods effectively prevents researchers from addressing important research questions and developing subsequent meaningful theory or robust scientific knowledge.

\subsection{Symbiosis between theory and scientific knowledge}

Understanding how a research contribution fits the theory building/testing cycle (i.e., its theoretical relevance and research method appropriateness) is the basis for its integration into the wider body of scientific knowledge (Hevner, 2007, p. 88). A cohesive and robust body of scientific knowledge cannot be formed atheoretically (Melnyk \& Handfield, 1998, p. 312; Reynolds, 1971, p. 9). The value of such theoretical framing is illustrated by design research contributions that have had an impact outside of the field. Among the 48 papers published in design journals cited in JPIM between 2010 and 2016, 33 demonstrate good-practice in delivering theoretical contributions in the form of, for example, research frameworks (Crilly, Moultrie, \& Clarkson, 2004, p. 569), generalizable definitions (Love, 2002, p. 358) or propositional directions for research (Gorb \& Dumas, 1987, p. 152; Redstrom, 2006, p. 136). In addition, all of the nine more empirically-orientated papers, explicitly frame their studies with respect to extant theory, in the form of testing predictions or offering refinements to scope or variables (Coughlan \& Mashman, 1999, p. 561; Person et al., 2008, p. 43). Further, two of the most frequently cited and scientifically impactful design research contributions, 'Function Behaviour Structure' by Gero (1990) (1977 citations ${ }^{1}$ ) and 'Co-evolution' by Dorst and Cross (2001) (1425 citations ${ }^{1}$ ), based on the work of Maher and Poon (1996), are also two of the most theoretically formalised studies. Each has spawned a specific body of knowledge, integrating numerous studies and insights connected via common concepts and principles. Linking research across a field builds on the identification, description and interconnection among common concepts, constructs and principles via theory (Eisenhardt \& Graebner, 2007, p. 1114; Reynolds, 1971, p. 83). Thus, explicit theoretical and methodological framing is essential to the development of robust scientific knowledge.

The development of theory is a prerequisite for internal cohesion and external accessibility (Briggs, 2006, p. 581). Theory facilitates interconnections across research methods, research settings and the contextual boundaries of subject 
and field (Eisenhardt \& Graebner, 2007; Melnyk \& Handfield, 1998). Without theory, it is difficult for researchers to understand, adapt or develop insights beyond the specific context in which they were generated (Friedman, 2003, p. 513; Robson \& McCartan, 2011, p. 31), which risks fragmentation and scientific stagnation. Also, the structuring of knowledge via theory allows researchers to more effectively direct research efforts, by identifying those parts of the body of knowledge that are incomplete, unclear or paradoxical (Melnyk \& Handfield, 1998, p. 313). For example, despite many studies on aspects of design cognition and behaviour, there was no cohesive description of how these aspects might be connected to provide a general model of design activity (Hay et al., 2017, p. 148) until the recent theory development work of Cash and Kreye (2017). This historical lack of theory has prevented design researchers from offering strong causal explanations of the progression of design activity. Thus, In the absence of a robust body of scientific knowledge, the steps in the theory building/testing cycle become disconnected, difficult to direct and difficult to link to prior research.

\subsection{Understanding and evaluating theory-driven research}

In addition to the three components of theory-driven research discussed in this section, there is a number of acknowledged manifest indicators of healthy theory-driven research. For example, a healthy symbiosis between theory building and the body of scientific knowledge means that there is a common understanding of the core concepts, constructs and principles, which allows links between research questions. In this context, meta-analytical studies can be developed based on an evaluation of these common elements. Thus, a clear indicator of a healthy link between theory and scientific knowledge is the existence of numerous and varied meta-analytical studies. These indicators help to identify comparable situations and challenges in other fields. In Table 1, each component of theory-driven research has a brief description linked to the main health indicators. For each component, I provide a link to the literature to show its importance and common characteristics across fields. For each health indicator, I highlight examples of good-practice discussions in the design literature.

\section{Challenges facing theory-driven design research}

I now examine the challenges facing current theory-driven design research (see Appendix). To support this discussion, I illustrate my points by contrasting design research with related fields. However, the comparison is not always direct since as different fields address different scientific challenges their internal structure changes. For example, it is common in more scientifically mature fields for there to be specialised review or method-focused journals. This reduces the number of review and method articles published in general journals, which would be more analogous to journals in design research. Where direct comparison is possible, I contrast design research findings to top ranked 
Table 1 The three foundational components of theory-driven research and their associated health indicators

Components of theory-driven
research

Theory building/testing

Associated to research clarity and explicit theoretical and empirical evaluation of research artefacts (Briggs, 2006; Eisenhardt, 1989; Hevner,

Manifest health indicators 2007).

- High levels of specific theory building research (Love, 2000).

- Consistent and explicit use of research frameworks to frame and connect empirical and theoretical contributions (Dorst, 2008).

- Consistent and explicit formalisation of theory application in both building, i.e., proposition development, and testing modes, i.e., hypothesis testing (Cash \& Culley, 2014).

Theory and method symbiosis Associated to research rigour and the interaction between theory and method use (Goetz \& LeCompte, 1981; Hevner, 2007; Levin \& O’Donnell, 1999).

Manifest health indicators

- High levels of specific methodology and method-focused research connected to the theory building/testing cycle (Blessing \& Chakrabarti, 2009).

- Consistent and explicit development and use of methods to identify research best practice (Ball \& Ormerod, 2000a).

- Explicit formalisation of methodological standards and procedures associated to development of both qualitative and quantitative evidence (Robinson, 2016).

Theory and scientific knowledge Associated to communication of research, self-evaluation and distillation of symbiosis

\section{Manifest health indicators} research knowledge (Glasgow \& Emmons, 2007; Hevner, 2007; Kitchenham, Dyba, \& Jorgensen, 2004).

- Widespread recognition and application of research on scientific knowledge development and the theory building/testing cycle (Horvath, 2016).

- High levels of specific meta-analytical and review-based research (Vasconcelos \& Crilly, 2016).

- Consistent and high levels of replication, reporting of negative results and data access (Crilly \& Cardoso, 2017).

general research journals in related fields that best match the scope and field specific aims of Design Studies. I use Design Studies as the starting point for the examples because it is both the highest ranked general design journal (Gemser et al., 2012, p. 12) and the journal that consistently represents the 'best case' in each aspect of the review results. Where direct journal-tojournal comparison is impossible, I contrast design research to research in the related fields more generally.

\subsection{Evaluating theory building/testing}

The first challenge is that despite a research tradition spanning 50 years, design theory is scant. This scarcity is highlighted by Love (2000, p. 312) and Dorst (2008, p. 7). However, only $3 \%$ of the papers reviewed (37 out of 1242) describe theory as a primary contribution. Further, few papers focus on developing rigour in the theory building/testing cycle. This contrasts to, for example, the Academy of Management Journal (AMJ) or JPIM, where an explicit contribution to theory is a prerequisite. In addition, major works on this subject (from design research and related fields) are not widely cited in the review, despite being recognised externally. For example, it is telling to compare the number of citations to key works in Design Studies with the 
number attracted in total (indicating their overall importance). During the review period, Eisenhardt's (1989) 'Building theories from case study research' received only two citations in Design Studies (out of a total 43696 citations $^{1}$ ), and Friedman's (2003) 'Theory construction in design research' received only three citations (out of a total 412 citations $^{1}$ ). This hinders attempts to answer how design insights might be connected within and across fields. This is particularly important, since the design literature includes a significant number of descriptive studies providing contextualised findings, which require theory for their integration. For instance, Crilly, Moultrie and Clarkson (2004) highlight that despite substantial study of user perception, further research development stalled due to lack of a linking theory. Thus, there is little evidence of specific theory development in design research and a lack of work examining how such development could be supported.

The few exceptions, such as 'Co-evolution' (Dorst \& Cross, 2001), almost exclusively offer descriptive explanatory knowledge - very few provide prescriptive, predictive or causal knowledge. For example, there is little formalisation of hypothesis testing (in theory testing mode) and its counterpart, proposition development (in theory building mode). In Design Studies, only five papers explicitly formalise propositions associated to theory building and predictive knowledge. Although some studies discuss predictions or causal claims (e.g., Dong (2005) examines predictions of increasing semantic coherence in design teams), there are almost no examples of integrated theory building/testing explicitly linking propositions and hypotheses. While 134 papers published in Design Studies discuss some type of experiment, only 79 formalise hypotheses. Contrast this to AMJ or JPIM where $100 \%$ of the papers published in 2016 explicitly describe either hypotheses or propositions. This lack of formalisation makes it difficult to judge what theory studies build on, what specific measures and concepts were used, and how they are linked. This is illustrated by McAlpine, Cash, \& Hicks (2017), who show that while there are many studies of how designers use logbooks, few offer general explanations of why logbooks are used. Therefore, the varied studies in this area are difficult to connect to a common theoretical lens, resulting in the majority of prescriptive attempts to develop, for example, digital e-logbooks, being unsuccessful. Thus, design research is not moving effectively through the theory building/testing cycle.

This insight leads to the second major challenge, the perceived fragmentation of knowledge (Love, 2002; McMahon, 2010) and the recognition that design research includes a high level of reinvention and rediscovery (Heymann, 2009, p. 242; Le Masson, Dorst, \& Subrahmanian, 2013, p. 3). This sense of 'reinventing the wheel' in design research is highlighted by Heymann (2009) with respect to recommendations for design in practice. The root cause of this problem is the difficulties related to formalisation, communication and interconnection of abstracted concepts, constructs and principles through 
theory. Without a linking theory, it is easy unintentionally to mischaracterise or fail to articulate the system under investigation (Robinson, Segal, \& Sharp, 2007, p. 547). This can be seen in the scarcity of research frameworks in the design literature. Research frameworks serve an explicit purpose of connecting diverse studies at an abstract level (Robson \& McCartan, 2011, p. 69). For example, only five papers in Design Studies make explicit reference to a research framework. Contrast this to $A M J$ or JPIM, where, in 2016, respectively $93 \%$ and $98 \%$ of papers describe the research framework used in their contribution. In addition, there is a lack of formalised connection in the design literature to the theory building/testing cycle, despite all of the steps in the cycle generally being represented. For example, in Design Studies, only four papers use the formal term 'theory building' and only two refer to 'theory testing'. This means individual research insights, despite being contextualised with respect to the literature reviewed, lack the formalisation and abstraction required to link them to wider scientific knowledge. Design researchers struggle to answer both descriptive questions about why design happens, for example, why a design tool works in the way that it does, and prescriptive or predictive questions about what might happen, for example, following the introduction of a new design tool. Without such interconnections among individual research insights, it is impossible to build theory or progress through the various steps in the theory building/testing cycle. Thus, design researchers lack the theoretical foundations necessary to provide compelling descriptive or prescriptive knowledge with respect to diverse underlying concepts.

\subsection{Evaluating theory and method symbiosis}

Given the above theoretical challenges and connections between theory and methods, we can expect to face a number of distinct methodological problems in design research (Section 1). These systematic challenges are strikingly evident in the design literature. The first is that design research lacks a formalised means for evaluating methods, deploying those best suited to a particular research question and, subsequently, integrating the results and assessing their quality. Few papers claim to contribute to research methods or research methodology (respectively $3.1 \%$ and $2.3 \%$ of those reviewed) and almost none focus on these aspects as their primary contribution. This contrasts to, for example, applied psychology (e.g., Morrow, 2007) and management (e.g., Bansal \& Corley, 2011), where methodological standards are accepted and form the basis for ongoing discussion. In design, very few papers claim to contribute by connecting theory to empirical methods $(1.1 \%$ of those reviewed), and none elaborate substantive methodological standards with respect to the theory building/testing cycle. This is despite similar standards being considered essential in fields such as management (Sparrowe \& Mayer, 2011) and software engineering research (Kitchenham et al., 2002). Thus, there is a general disconnect between the theory building/testing cycle 
and the methods used in design research, and an overall lack of field specific research on method development and application.

The impact of this problem on design research is illustrated by the metaanalysis by Sio, Kotovsky, and Cagan (2015) and the systematic review provided by Vasconcelos and Crilly (2016), both of which explore trends in experimental studies of fixation. Given that fixation is an established theory and its experimental methods are oriented towards meta-analysis, comparison in this area should be straightforward. However, Sio et al. (2015, p. 95) were forced to limit their sample to a small subset of fixation experiments and, ultimately, concluded that their analysis was likely underpowered with respect to the range of fixation effects considered. Vasconcelos and Crilly (2016, p. 26) offer a partial explanation for this limitation, highlighting the high degree of variation in experimental methods and the vagueness with which fixation theory is defined and used to frame experimental effects. This exemplifies how, without supporting theory, it is difficult to define comparable methods, which, in turn, hampers effective theory building (Crilly \& Cardoso, 2017, p. 21). The fact that meta-analysis was severely limited, even in the relatively cohesive fixation research theme, is a major indicator of the lack of standardisation in methodological and evidential practices. This makes it impossible to develop theory in a field, such as fixation, or identify meaningful insights regarding its effects in design.

This leads to issues in developing and validating robust research methods associated to each of the steps in the theory building/testing cycle. A number of works discuss qualitative methodologies and methods and how these might be developed to better respond to the needs of design research (Collins, Joseph, \& Bielaczyc, 2004; Reich, 2010; Robinson, 2010). However, with respect to quantitative methods, there is substantially less support, and the disconnect between theory and methods is more pronounced (Cash \& Culley, 2014, p. 182). This is particularly significant in the context of the higher reliance of quantitative methods on explicit theoretical framing (Kirk, 2009, p. 23). A major feature of this issue is that almost no 'gold standard' methods for examining generalised causal claims are available in the reviewed literature, that is, meta-analyses (Glass, 1976), RCTs (Haidich, 2010) or robust experiments (Grimes \& Schulz, 2002). This is despite such claims underpinning many design research contributions, and the tradition in design research of varied experimental studies (Cash, Elias, Dekoninck, \& Culley, 2012; Robinson, 2016). Only two papers published in Design Studies mention methodological best practice in the context of research methods, empirical investigation or theory building. Also, I found no research dealing with methodologically inclusive standards of evidence or rigour. This is notwithstanding the need for such standards being discussed in several editorials (Cross, 2012; Reich, 2010) and being highlighted by Vasconcelos and Crilly (2016, p. 26) and Cagan et al. (2013, p. 1). The general need is underlined 
by numerous authors (Glasgow \& Emmons, 2007, p. 421; Grimes \& Schulz, 2002, p. 60; Kitchenham et al., 2004, p. 278) and these standards are accepted in closely related fields such as general management (Bansal \& Corley, 2011) and software engineering research (Kitchenham et al., 2002). Flay et al. (2005, p. 171) highlight the positive role played by such standards in bringing a research field together, and they emphasise the general value of standards when assessing evidence and research quality, and communicating with practitioners. The lack of methodological development, validation and standardisation prevent design researchers from responding to key research questions about the nature of design phenomena, and developing effective design theory (Wacker, 2008, p. 7). In addition, it limits design researchers' ability to provide convincing evidence to researchers in related fields where such standards are common. Thus, design researchers lack the methodological tools required to address the deep descriptive and prescriptive questions that form the foundations of theory-driven design research.

\subsection{Evaluating theory and scientific knowledge symbiosis}

The interaction between theory, methods and the development of scientific knowledge allow the identification of a number of distinctive challenges (Section 1). The first is that design research struggles to develop a cohesive body of scientific knowledge. Only $1.2 \%$ of the reviewed design papers describe their focus as connecting theory building/testing work to a body of scientific knowledge via review or analytical research. None of the papers reviewed dealt with the development of an overall model for design research, that is, connecting the theory building/testing cycle, application domain and body of scientific knowledge. In addition, major works on this topic from related fields were not widely cited in the design literature. For example, Eisenhardt's (1989) case-based explanation of theory building was cited only twice in Design Studies during the review period. These findings contrast to the findings for $J O M$ or JPIM, for example. Both journals include a high proportion of papers focused on linking theory building/testing efforts with a body of scientific knowledge via review or analytical research (circa 16\% between 2010 and 2016). Further, Eisenhardt's (1989) work was cited over 150 times in these two journals in the same period. This lack of knowledge development means that design researchers struggle, for example, to connect proposed design tools or interventions to underlying theory. This is illustrated by Daalhuizen (2014, p. 155), who highlights the disconnect between proposed design tools and theories of human behaviour, resulting in low levels of utilisation of tools in practice. Thus, there is little work in developing a cohesive body of scientific knowledge.

The perception of fragmentation and reinvention in design research, already discussed, is indicative of the second major challenge, that is, a general lack of formalised analytical research and reflection. The absence of commonality 
and structure provided by the theory building/testing cycle and the evidence it provides, means that there is no a robust analytical research tradition in design research. This excludes half of the methods available to a researcher (Wacker, 1998, p. 376), evidenced by the single meta-analytic study (Sio et al., 2015), lack of falsification studies and the fact that only $1.2 \%$ of papers focus on review and critique. No major design journal or conference includes tracks focused on analytical research methods. Further, although there are some more narrative reflective works, for example, Cross $(1993,2007)$ and Sheldon (2004, 2006), these are few in number and represent only a tiny fraction of the reviewed literature. It is interesting that the value of such formal reflective study is recognised with respect to design practice in Spitas's (2011) survey of design paradigms in industry, but not with respect to design research.

Contrast the above lack with the general management or applied psychology literature where three of the top ten journals in both fields are dedicated outlets for review and analytical research (Liang et al., 2015). These journals are central in their fields. For example, the Annual Review of Psychology and Academy of Management Review are ranked respectively 1 st and 2 nd in their fields. In the absence of such a tradition, it is difficult to generalise findings or to connect them across the various steps in the theory building/testing cycle (Heymann, 2009; Le Masson et al., 2013). In addition, without formalisation and recognition of analytical methods, it is difficult for a field to build on past research or effectively to critique its own practices. This is damaging to efforts to more systematically direct research by identifying those parts of the body of scientific knowledge that are incomplete, unclear or paradoxical. Further, design researchers produce knowledge that is difficult for external researchers to access because it lacks analytical research on major theoretical developments that, typically, form the foundations for cross field communication (Melnyk \& Handfield, 1998, p. 313). Thus, answering questions about the relevance of design research with respect to theory in other fields, or how design studies can be combined to assess the general value of design insights becomes problematic and has negative effects on design research uptake and impact.

Connected to the above issue is a third more pragmatic challenge. Design research lacks the formalised approaches to the theoretical framing and reporting of research necessary to support systematic self-reflection and critique. This hampers effective meta-analytical and other systematic review efforts. For example, key quantitative research mechanisms in this context include replication, analytical studies, negative reporting and investigation of systemic biases. None of the papers reviewed mention replication as a concept relevant to design research methodology. This is despite the fundamental role of replication in experimentation highlighted by Kirk (2009, p. 24) and others (Maxwell et al., 2015; Tsang \& Kwan, 1999), and the widespread use of experimental methods in design research (Cash, Stankovic, \& Storga, 2016b, p. 5). Similarly, key qualitative mechanisms include investigations into the interconnection of 
insights, falsification and triangulation (Flyvbjerg, 2006; Nock, Michel, \& Photos, 2007). Again, this research is limited in the design literature. This means that design researchers struggle to generate strong evidence-based statements about the state of research in the design field. It is impossible to know whether a study provides convincing results atheoretically, to evaluate how well potential errors or research biases have been mitigated in a single experiment without replication, or to judge whether the phenomena studied are robustly generalizable without meta-analysis and falsification criteria.

In addition to the above, key practical mechanisms for generating commonality and theoretical integration are scarce in design research. For example, there are few open study protocols, tasks or datasets. A notable exception here are four Design Thinking Research Symposia (DTRS) that employ this approach. However, they are a minority even within the DTRS series (Cross, 2017, p. xi), and there is no exploitation of common datasets elsewhere in the design literature. In particular, there are no papers focussing on research triangulation, despite its fundamental role in the theory building/testing cycle (Robson \& McCartan, 2011, p. 171) and its explicit relevance to multi-perspective studies such as DTRS. Similarly, the 'peanut sheller' task, popularised by Linsey, Green, Murphy, Wood, \& Markman (2005, p. 4) and others (Fu, Cagan, \& Kotovsky, 2010; Linsey, Markman, \& Wood, 2012), is a rare exception. In general, the reviewed design journals lack data publication, negative reporting and other mechanisms standard in this context. Thus, there is a major deficit in the practical support for systematic self-reflection and critique in design research.

Taken together, these challenges mean that design research is subject to a memory problem whereby evidence becomes lost, and researchers must reinvent or redevelop insights with every change to context or subject. It is difficult, also, to provide robust support for research claims across fields because standard mechanisms intended to evaluate and aggregate evidence within a field (e.g. systematic review, replication etc.) are lacking in design research. Thus, design researchers lack the reflective tools necessary to address questions about research quality, effectiveness of prescriptive proposals, or robustness, validity and generalisability of insights across fields.

\subsection{Overview of the challenges facing design research}

While individual researchers might find the problems described in this section difficult to address, as a field we cannot pretend that they do not diminish the overall impact of design research. Lack of systemic integration of theory in a research field means that insights cannot be generalised or adapted more widely and applied in new contexts. For example, while, as a design researcher, I might be able to bring together the literature on a topic and formulate my own 'theory' connecting the elements involved to frame an experiment, judging each empirical study with respect to its context and method, this 
process is near impossible for a researcher external to design. For example, the external researcher must, first, connect to the fragmented concepts, constructs and principles, often described purely empirically without a research framework, structuring design theory or links to wider cross-field theory. Second, an outsider must judge the empirical descriptions of these elements with little basis for assessing the quality of the research methods used, no standard for reconciling potentially conflicting results, and no means to recourse to examples of methods acknowledged as gold standards across fields. Third, the researcher must build on evidence that often is either not verified or is unverifiable, even within design research. In addition, the field of design research is unable to provide evidence on major research biases or systemic issues in the insights offered. This forces related fields to re-invent and re-study contributions, rendering the contribution of design research moot. Thus, it must be concluded that although each individual researcher may strive to do the best work possible, there are major challenges in the field. These are summarised in Table 2 together with the supporting evidence from the review.

\section{A way forward}

Studying the fields that have dealt with challenges similar to those outlined in Section 2, allows identification of a way forward for theory-driven design research.

\subsection{Fostering greater theory building/testing}

The first major feature of the improvement efforts across related fields is the establishment of a robust scientific model linking the different components

Table 2 The challenges facing theory-driven design research

\begin{tabular}{|c|c|}
\hline Challenges and evidence & Summary description \\
\hline Theory building/testing & $\begin{array}{l}\text { Developing a robust tradition of theory building/testing in design } \\
\text { research as well as connecting to fields outside design. }\end{array}$ \\
\hline \multicolumn{2}{|c|}{$\begin{array}{l}\text { Evidence } \\
\text { - Low levels of specific theory building research. } \\
\text { - Little explicit use of research frameworks to frame and connect empirical and theoretical contribution. } \\
\text { - Little explicit formalisation of theory application in either building or testing modes. }\end{array}$} \\
\hline Theory and method symbiosis & $\begin{array}{l}\text { Developing robust methods such that design research insights } \\
\text { might support greater theory building and impact across fields. }\end{array}$ \\
\hline \multicolumn{2}{|c|}{$\begin{array}{l}\text { Evidence } \\
\text { - Low levels of specific methodology and method focused research connected to the theory building/testing cycle. } \\
\text { - Little explicit development of methods linked to the building of standards of practice. } \\
\text { - Little explicit formalisation of methodological standards and procedures. }\end{array}$} \\
\hline $\begin{array}{l}\text { Theory and scientific knowledge } \\
\text { symbiosis }\end{array}$ & $\begin{array}{l}\text { Developing an integrated body of scientific knowledge in design } \\
\text { research that is accessible to both design and other researchers. }\end{array}$ \\
\hline \multicolumn{2}{|c|}{$\begin{array}{l}\text { Evidence } \\
\text { - Little recognition and application of research on scientific knowledge development and the theory building/testing cycle. } \\
\text { - Low levels of specific analytical research methods. } \\
\text { - Little replication, reporting of negative results, or open data access. }\end{array}$} \\
\hline
\end{tabular}


of theory-driven research. The development of such models is aimed at creating a structure to allow researchers to connect diverse research methods, theory building/testing and the body of scientific knowledge, to generate theoretical and practical impact. Also, the process of creating a scientific model is almost as valuable as the model itself (Colquitt \& Zapata-Phelan, 2007, p. 1293; Winter, 2008, p. 474). The development and application of a scientific model is a common feature of improvement efforts in information systems (Briggs \& Schwabe, 2011), education (Gorard \& Cook, 2007), management (Eisenhardt \& Graebner, 2007) and psychology (Smith \& Conrey, 2007). For example, Gorard and Cook's (2007) work discusses the process of forming such a model. Gorard and Cook bring together two streams of 'conflicting' research and distil their common elements in order to describe a fundamental scientific model for education research. This highlights not only the foundational nature of such a model but also its role in helping to bring together diverse fields. In addition, Gorard and Cook's work illustrates how a scientific model can be adapted from a more generic theory building/testing cycle, to the context of a specific field. This adaption and field specific description is reflected in other work, such as Eisenhardt and Graebner (2007) and Colquitt and Zapata-Phelan (2007) in management research, and Smith and Conrey (2007) in social psychology. It is possible to envisage similar development efforts in design research, either building on one of the models mentioned here or focused on a field-specific model. Thus, a scientific model forms the foundation for clarifying and integrating research within a field, and forms the basis for more specific improvement efforts associated to each component of theory-driven research. This allows researchers to connect insights from across contexts and organisational levels, and to link descriptive questions about why phenomena occur, to prescriptive questions regarding, for example, the impact of new design tools or interventions.

The second major feature of improvement efforts across the related fields is that they establish tenets of 'good' theory-driven research, building on an underlying scientific model. This effort is aimed at reinforcing the explicit connection to the theory building/testing cycle, and moving towards a stronger tradition of theory-driven research in general. For example, a focus on theory building/testing characterises the transition of operations management from a highly applied empirical field to an influential theory building field (Melnyk \& Handfield, 1998). A similar development of field specific research on theory building/testing is typical also of self-improvement efforts in education (Gorard \& Cook, 2007) and information systems (Gregor \& Jones, 2007). These research fields have sought to establish, for example, the specific nature of the challenges in the theory building/testing steps (Gorard \& Cook, 2007, p. 13), the virtues and characteristics of robust theory-driven research in each step (Wacker, 1998, p. 364), and how these insights can be applied to generate greater practical and scientific impact within and across fields (Levin \& O'Donnell, 1999, p. 220). A similar approach would allow design researchers 
to, for example, more systematically evaluate the likelihood that efficacy claims associated to a proposed design tool are robust, and that the design tool will have the expected impact when applied in a new context. Such tenets of good practice allow researchers to evaluate the strength of both descriptive and prescriptive claims, and to evaluate how they might be translated into new contexts.

In addition to prioritising research on theory building/testing, there have been parallel efforts to adopt, adapt and connect to theories from other fields in order to kick-start a tradition of theory-driven research (Colquitt \& ZapataPhelan, 2007, p. 1294). These efforts provide an immediate bridge to other areas of impact, and constitute a first step towards best practice, which can be difficult to establish in the context of a weak theory-driven research tradition. For example, they are a crucial part of the rationale for Bedny and Harris's (2005, p. 128) refinement and application of activity theory in education, and Sowden et al.'s (2015, p. 40) application of dual process theory in creativity. In design research, these efforts could take the form of specific publications adapting principles of theory-driven research to the design context, or foundational reviews of theories relevant to design. Alternatively, the development of a database listing design relevant theories and their constituent elements might constitute a more pragmatic approach. Such databases are becoming more frequent in related fields (Larsen, 2015; NCIB, 2015; Poldrack et al., 2011). For example, the Inter-Nomological Network (INN) (Larsen, 2015) provides a database of variables and links them to larger constructs and specific instantiations of their use. A key element supporting all these efforts is the systematisation of concept, construct and principal descriptions across a field (Colquitt \& Zapata-Phelan, 2007, p. 1296). This would allow design researchers to explicitly connect to work in other research areas, or work conducted in other contexts, and would provide a direct means for achieving impact in other fields.

The third major feature of improvement efforts across fields is the formalisation and use of a research framework. Research frameworks explicitly link the base theory under investigation to other related concepts, constructs or principles in order to bridge across field boundaries (Gregor \& Jones, 2007; Walls, Widmeyer, \& El Sawy, 1992). Research frameworks are a crucial ingredient in discussions of the purpose, scope and contribution of a piece of research in the wider theory building/testing cycle. As such, research frameworks can connect both qualitative and quantitative methods to provide a foundation from which to explicitly link elemental studies to the wider theory or knowledge (Snow \& Thomas, 2007). Formalisation of research framework use is at the heart of development efforts in management (Malhotra \& Grover, 1998; Snow \& Thomas, 2007), psychology (Michie, Johnston, Francis, Hardeman, \& Eccles, 2008) and software engineering research (Kitchenham et al., 2002). The importance of research frameworks can be seen in the management 
domain in the gradual integration of information processing constructs from diverse studies, and across organisational levels, to create organisational information processing theory (Daft \& Lengel, 1986; Hultink, Talke, Griffin, \& Veldhuizen, 2011). Although description of a research framework in an individual paper might seem trivial, it is an important step in the explicit linking of studies to form a cohesive body of scientific knowledge (Barab \& Squire, 2004; Hitt, Beamish, Jackson, \& Mathieu, 2007). Thus, research frameworks are important for generalising research findings and allowing practitionerled or practice-focused work to be incorporated into the wider research (Sandoval \& Bell, 2004). For example, research frameworks help researchers translate observations of design work into specific design tool prescriptions. Systematic application of research frameworks would allow design researchers to directly link diverse works from across the range of descriptive and prescriptive research questions in order to increase scientific impact within and across fields.

\subsection{Fostering greater symbiosis between theory and method}

Significant for the development of an effective link between theory and method is systematic development of methodological best practice based on the research questions posed, and the nature of the theory under investigation. I think that research, particularly in the behavioural domain, necessarily builds on a synthesis of the evidence from qualitative and quantitative, analytical and empirical methods with none taking priority in the overall context of the theory building/testing cycle (Goetz \& LeCompte, 1981, p. 53). However, it is possible to identify more or less appropriate methods with respect to their specific application (Handfield \& Melnyk, 1998, p. 324), and to define what characterises good practice and robust evidence in these applications (Grimes \& Schulz, 2002; Malterud, 2001).

Connecting method development to the theory building/testing cycle is central to self-improvement efforts in education (Levin \& O'Donnell, 1999), health (Seale \& Silverman, 1997) and behavioural (Tashakkori \& Teddlie, 2008) and management science (Molina-Azorin, 2010; Onwuegbuzie \& Leech, 2006). In each case, greater prioritisation of method integration led to explicit discussion of which methods and which research questions fit best, and how to assess the quality of the evidence produced. For example, Gorard and Cook (2007, p. 321) state that 'For a given kind of question, one method is often superior to another. It is only across all of education research with its many different kinds of question that multiple methods are needed' and, further, that to test generalized causal claims ' $R C T$ s are the best available primary method'. In contrast, Flyvbjerg (2006, p. 11) suggests that case studies are ideal for testing contextualised claims because they provide deep insights and potential falsification. In both cases, the authors acknowledge that objective standards of rigour and evidential quality can be established for specific research questions. 
Thus, it is possible to envisage similar development efforts in design research, either building on works such as Amundson (1998), or elaborating prior discussions of specific methods in the design domain (Ball \& Ormerod, 2000b; Robinson, 2016). This would allow design researchers to better match their research approach to descriptive or prescriptive questions, and to identify areas of methodological weakness in design research.

Exploring the idea of standards further, efforts have been made to provide guidelines for both qualitative and quantitative methods in several fields including management (Amundson, 1998; George, Haas, \& Pentland, 2014), prevention science (Flay et al., 2005), education (Freeman, Preissle, Roulston, \& Pierre, 2007) and health research (Brennan, Castro, Brownson, Claus, \& Orleans, 2011; Glasgow \& Emmons, 2007; Johnston, Sherer, \& Whyte, 2006). A typical example can be taken from the clinical domain, where Grimes and Schulz (2002, p. 57) describe an evidence hierarchy for causal research claims, identifying three generic elements associated to strong evidence: comparison of the method against an agreed standard for its execution; rigorous randomisation; and effective control. Some more recent works extend this by describing meta-analyses aggregating good RCTs as the gold standard analytical method, and RCTs as the gold standard empirical method, in this specific context (Haidich, 2010, p. 30; Ioannidis, 2005, p. 225). Also, other authors, such as Gottfredson et al. (2015), discuss standards with respect to the application and development of research from theory to 'effective' recommendations for practice. Similarly, Malterud (2001, p. 485) propose guidelines for assessing qualitative methods, while others discuss the standardisation of reporting, for example, the contextual factors affecting method application (Dillon, 2006, p. 71; Kitchenham et al., 2002, p. 723). An example of how standards from medicine and psychology can be adapted to an applied field such as design research, is provided by Kitchenham et al.'s (2002) 'guidelines for empirical research' in software engineering. Similarly, Levin and O'Donnell (1999) propose the CAREful approach in education. Importantly, Flay et al. (2005) and others (Brennan et al., 2011; Glasgow \& Emmons, 2007) point to the generally positive impact of developing methodological and scientific standards. Standards and stronger linking to a field's scientific models have proven powerful means for improving and integrating research in a field, for example, by describing how both qualitative and quantitative methods can be used effectively to develop theory. Also, discussion of these standards is critical to the adoption, development and validation of new research methods. For example, they form a core part of discussions on big data techniques in general management (George et al., 2014). Given the highly structured nature of standards and their relative commonality across fields, a standard for design research could be developed in a collaboration involving the major design journals or design research societies, for example. This would allow design researchers to explicitly evaluate and communicate the quality of the evidence 
provided for a given research question, and to connect design research evidence to work in other fields via shared standards of rigour.

Practically, there is a number of general steps to improving the connection between theory and method. These include: the development of specific methodologically focused journals or tracks within a field, for example, the Journal of Educational and Behavioral Statistics; the integration of formalised abstracts, which emphasise methodology and correlate to improved research quality (Taddio et al., 1994); and the development of systematic approaches to the selection and combination of methods (Cash \& Snider, 2014; Hanson, Creswell, Plano-Clark, Petska, \& Creswell, 2005). These steps are supported by systems that allow study data and protocols to be available in published research, as is common in psychology or medicine. Such systems are a prerequisite for effective meta-analytical research (Haidich, 2010; Ioannidis, 2005). Another way to ensure monitoring of studies and reporting of negative findings is the study registration system in medicine e.g. ClinicalTrials.gov. All of these efforts highlight robustness and research rigour, while supporting the more effective critique and reflective analysis described by Wieseler, Kerekes, Vervoelgyi, McGauran, and Kaiser (2012, p. 6). These sorts of efforts, generally, support the connection between theory, method and the specific body of knowledge based on the fields' scientific models. In the case of design research, it would allow the collection of larger datasets, easier comparison of methods, results and evidence, provide answers to new descriptive and prescriptive research questions, and allow more transparent communication of the robustness of design research across fields.

\subsection{Fostering greater symbiosis between theory and scientific knowledge}

Development of a scientific model is the main foundation to the integration between theory-driven research and the body of scientific knowledge. However, there is a number of other approaches used to forge stronger links between theory and scientific knowledge. These include development of a tradition of critical qualitative and quantitative reflection (Maxwell, Lau and Howard., 2015; Neuliep, 1991), use of both analytical and empirical research methods (Robson \& McCartan, 2011; Scandura \& Williams, 2000), and practical systematic support for these efforts.

The fundamental pre-requisites for effective quantitative or quantitative reflection are clarification of theoretical elements, methodological standards and transparent data reporting (DerSimonian \& Laird, 1986, p. 178; Malterud, 2001, p. 485). However, this involves a co-evolutionary process in which effective reflection depends on and also drives scientific development and methodological rigour. An example of this co-evolution is the work by Dyba and Dingsoyr (2008), which derives key scientific findings 
in software engineering while, simultaneously, highlighting methodological and reporting issues that prevent further insights. Thus, effective reflective practices support the questioning of tradition and the building of new, more effective methodological and scientific paradigms. It allows design researchers to respond to important descriptive and prescriptive research questions about the nature of design work, including how context affects the outcome of design tools or interventions, how design is changing over time due to new technologies or practices, and where specific gaps or weaknesses in prior research are emerging.

Reflection relies on the effective combination of reporting, methodological standards, clear research frameworks and a wider scientific model. Historically, reflection has been significant in clinical research (Glasgow \& Emmons, 2007; Sackett et al., 1996). Here, it feeds into three major streams: quantitative meta-analysis for aggregation; quantitative and qualitative meta-analysis for methodological assessment; and qualitative analysis for scientific reflection. An important commonality across fields involving all three streams is the concerted effort to recognise the value of these analytical methods. For example, the Academy of Management Review and the Psychology Review focus specifically on reflection in their respective fields. In addition to acknowledging the value of this work, we need specifically to foster a culture of negative reporting, critical self-reflection, falsification and replication (Fanelli, 2015). Below, I give three examples of the relevance of reflection to the problems faced by design researchers. First, in design, there are numerous lowpowered experimental studies. Boutron, Dutton, Ravaud, \& Altman (2010) provides a review of work that focuses on prescriptive causal claims and shows that the reporting and interpretation of findings are frequently not consistent with the results. This highlights the need in empirical studies for specific interventions and reflection across studies and methods. Second, the results of design research often are contradictory or unclear, as illustrated by the contrasting fixation studies described in Vasconcelos and Crilly (2016). Ioannidis (2005) examines situations where highly cited studies are subsequently contradicted and describes how contradiction and initially stronger effects are not unusual. This highlights the need for aggregation, falsification and other methodological means for integrating evidence across settings. Finally, design research involves many prescriptive suggestions related to design tools that, in practice, should have a positive impact. In medicine, Poynard et al. (2002) found that the survival and uptake of research by practitioners is highly dependent on the quality of its prognostic factors, that is, objectively measurable factors that provide information on the likely outcome of an intervention. Similar studies would allow design researchers to provide evidence of design insights credible in other fields, to describe how key design insights might evolve over time, and to identify those aspects of methodology and evidence driving impact. 
In the area of negative reporting and critical self-reflection, a number of studies across disciplines have highlighted the dominance in the literature of positive findings. See, for example, Vasilev (2013) in psychology, Fanelli (2015) in scientometrics, and Honig et al. (2017) in management. In all these cases, specific efforts were required to encourage the full reporting of studies. These include study registration, creation of specific outlets (for example, the Journal of Negative Results in Biomedicine), use of meta-analysis, and confrontation of ethical and systematic issues that bias data reporting and scientific practices (Honig et al., 2017). Practical and structural support for systematic reflection would allow design researchers to identify potential biases or systemic issues and, subsequently, work to eliminate these, thus increasing design research credibility across fields.

\subsection{Recommendations for future theory-driven design research}

By drawing on the insights discussed in this section, I provide some important learning for future theory-driven design research. A major consideration in applying this learning is that it is interlinked and mutually supporting - advances in one component are linked to advances in other components (Section 1). Also, in many cases, the discussion, development and adaption of this learning is a crucial part of its benefits in a field (Honig et al., 2017). This is illustrated by the integrative effect of the standards proposed in Kitchenham et al. (2002). Not only did it provoke debate over scientific rigour, it also helped to foster more general discussion on the future direction of improvements in software engineering research. This is an example of the task facing design research. Concerted efforts over more than a decade were required to address many of the major problems in software engineering research.

In the case of design research, the preliminary steps have been taken in works such as Love (2000), Dorst (2008), and McMahon (2012). Here, I focus on solidifying the learning provided in this section into general recommendations for design research as a whole, and specific recommendations for design researchers (whether as authors or reviewers). These recommendations are presented in Table 3 with respect to each component of theory-driven research. Pragmatically, these recommendations can be considered a checklist of questions that design researchers should address when developing their next study. For each recommendation, there are existing guidelines and standards in related fields. Although many of these recommendations have yet to be formalised in design research, this does not mean that changes cannot be made to the conduct of design research.

Ultimately, these recommendations indicate the need for major change at field (including community, journals and conferences) as well as at the individual researcher levels. Priority should be given to theory-driven research, awareness 
Table 3 Guidelines for future theory-driven design research

Theory building/testing

General recommendations for the field

1. Formalise a scientific model adapted to design research, connecting methods and methodology, the theory building/testing cycle, the development of a body of scientific knowledge, and changes to practice.

2. Identify and formalise the steps comprising the nature and tenets of good theory building/testing in design research.

3. Formalise use of research frameworks linking variables to theory, as a core element of both qualitative and quantitative design research.

4. Support aggregation of theory, e.g., via databases of studies and theoretical elements.

Specific recommendations for individual researchers

- Ensure explicit positioning of the research within the theory building/testing cycle.

- Ensure explicit description of the research framework together with the core tenets of the theory underpinning the research.

- Ensure adherence to best practice appropriate to the position in the theory building/testing cycle, the research question and the theory being tested.

Theory and method symbiosis

General recommendations for the field

5. Formalise research and evidential standards with respect to both qualitative and quantitative research paradigms connected to the underlying theory building/testing cycle.

6. Prioritise methodological research within the field, e.g., via structured abstracts, dedicated journals and work focused on how to integrate methods and design theory.

7. Support aggregation of methods and data, e.g., via facilitating data and protocol publishing.

Specific recommendations for individual researchers

- Ensure the method selected is connected explicitly to the theory building/testing cycle and research question, and benchmarked against other research addressing similar questions.

- Ensure methodological best practice and evidential standards are described explicitly with respect to the targeted theoretical contribution.

- Ensure availability of supporting documentation, e.g., study design and protocols, and, where possible, datasets, and ensure the research can be replicated or falsified where appropriate.

Theory and scientific knowledge symbiosis

\section{General recommendations for the field}

8. Formalise practices surrounding contribution to the body of scientific knowledge linking qualitative and quantitative research via the scientific model.

9. Prioritise critical review and meta-analysis, e.g., via dedicated journals or tracks.

10. Practical support for data reporting, study recording, replication and negative reporting.

Specific recommendations for individual researchers

- Ensure that the generic elements of the theory being studied are explicit and highlighted such that other researchers can connect to them, in both design research and other fields.

- Ensure that, wherever possible, the measures and methods used include standard elements to facilitate meta-analytics.

- Ensure that where appropriate data are made available for re-analysis or replication, and that negative results are not ignored.

of its merits and virtues, development of its practices, and specific scientific and practical support for its application. Thus, in proposing a new paradigm of theory-driven design research, I envisage an explicit link in the vast majority of papers to the theory building/testing cycle. In this new paradigm, researchers from related fields should have access to design research inarguably grounded in robust theory, supported by validated methods and evidence, and communicated via a fundamental characterisation of concepts, constructs and 
principles linked via accessible theory. Rather than reinventing design research, the related fields will be able to connect to, build on and elaborate our work.

\section{Conclusions}

Design research faces the stark choice of taking action to increase scientific, theoretical and methodological rigour and seizing the potential for scientific and practical impact across fields or becoming obsolescent. The former involves the overturning of the status quo. We can no longer continue 'doing what has always been done'. A new paradigm of theory-driven design research is needed to face the significant challenges that exist. Although a paradigm shift will not be easy, the potential benefits will be substantial, particularly given the opportunity presented by growing interest in design across related fields. We can no longer afford to ignore this message.

In this article, I provide a foundational introduction to theory-driven design research, elaborate the challenges facing the field in this context, and seek to distil concrete recommendations based on insights from related fields that have successfully navigated similar situations. This paper should be seen as the starting point; design researchers must question themselves and the field for these recommendations to have an impact. A dialogue is needed in which reflective works identifying the challenges and suggesting mitigations to them become the norm in design research as in related fields.

\section{Acknowledgements}

I would like to acknowledge, and express thanks for, the substantial and constructive input provided by the Design Studies reviewers as well as Prof. Cross. Further, I thank Dr. Kreye for providing invaluable input and criticism throughout the development process. Finally, I thank Prof.'s Hicks, Culley and McMahon for their feedback and discussion at various stages in the maturation of this work.

\section{Appendix. Review procedure}

The review follows a mixed methods approach (Grant \& Booth 2009), combining systematic and critical review of the design research literature. The systematic element of the review is based on the work of Higgins et al. (2008) which is aligned to the application in Kitchenham et al. (2004; 2009). I adopt a number of scoping definitions that bound the review and my discussion of design research. Specifically, I focus on 'general design' research outlets as distinguished and ranked by Gemser et al. (2012, p. 12). Further, I follow the definition of design in Galle (1999, p. 79): 'design(ing) as production of a design representation', and the definition of design research in Blessing (2003, p. 9): 'Design research aims at increasing our understanding of the phenomena of design in all its complexity and at the development and validation 
of knowledge, methods and tools to improve the observed situation in design'. For a detailed discussion of this conceptualisation, the seminal works of Cross (1999) and Horvath (2004) further define the nature and scope of design research as a field. Given this scope the following journals were examined:

Journals examined (papers in range): Design Studies (328), Design Issues (361), International Journal of Design (IJD) (119), Journal of Engineering Design (JED) (260), Research in Engineering Design (RIED) (156), Design Science (18).

These represent the top four 'general design' research journals, Design Studies, Design Issues, JED, and IJD, according to Gemser et al. (2012, p. 12). These form the basis for general comparisons throughout the paper. RIED was included to provide an additional perspective on design research and to check the findings emerging from the general design journals. RIED was selected for this purpose since it is the highest rated journal in engineering design (Gemser et al., 2012, p. 12). Similarly, the new journal Design Science, was included in order to examine the current state-of-the-art in a design journal without preexisting historical constraints. As a new journal Design Science should reflect current perspectives on best practice.

Search criteria: all papers; 2010-2016; abstract, title or keywords.

Initial search terms: research methods, methodology, theory, empirical, meta, repeat, replication, critical, review, triangulation.

Total papers in range: 1242.

Papers were identified, initially, by keyword and then filtered and allocated to different topic foci based an assessment of the papers themselves. Papers not focused on one or more components of theory-driven design research, outlined in Section 1, were removed from consideration for the purposes of the systematic review. This did not exclude them from the critical review. In this process papers could have more than one focus area, for example, both theory development and research methods. In such cases, the papers were counted in both categories. Thus, the total number of unique papers is smaller than the sum of the topics listed below.

A limitation of this methodology is that the extent of specific features in the literature can be over/under estimated in summary statistics. This is mitigated in two ways. First, the critical review serves to develop and contextualise the findings, providing insights into the tangible impact on the design field associated to these results. Second, the search terms reflect a range of standard descriptors, for example, for theory and, thus, cover most of the formal scientific terminology in this context. 


\section{Papers sorted by focus of their research contribution:}

Theory

Empirical research

Research methods

Methodology

Research triangulation

Meta-analysis

Replication or study repetition

Critical review
37

$3.1 \%$

$28-2.3 \%$

$0 \quad 0 \%$

$1-0.1 \%$

$0.4 \%$

$15-1.2 \%$

Evaluation criteria: Theory building, method symbiosis and scientific knowledge symbiosis have a number of distinct features that are considered indicative of healthy, theory-driven research across fields. These were used as the basis for a detailed evaluation of the identified works. Theory building was evaluated based on research clarity and the explicit theoretical and empirical evaluation of research artefacts (Briggs, 2006; Eisenhardt, 1989; Hevner, 2007). Indicators of health are (each indicator is connected to prior discussions of such topics in the design literature):

- High levels of specific theory building research (Love, 2000);

- Consistent and explicit use of research frameworks to frame and connect empirical and theoretical contribution (Dorst, 2008);

- Consistent and explicit formalisation of theory application in both building, i.e., proposition development, and testing modes, i.e., hypothesis testing (Cash \& Culley, 2014).

Method symbiosis was evaluated based on the level at which theory and methodology are specifically connected in design research. This is associated particularly to research rigour and the interaction between use of theory and method (Goetz \& LeCompte, 1981; Hevner, 2007; Levin \& O’Donnell, 1999). Indicators of health are:

- High levels of specific methodology and method focused research connected to the theory building/testing cycle (Blessing \& Chakrabarti, 2009);

- Consistent and explicit development and use of methods, building research best practice (Ball \& Ormerod, 2000a);

- Explicit formalisation of methodological standards and procedures associated to developing qualitative and quantitative evidence (Robinson, 2016).

Scientific knowledge symbiosis was evaluated based on the level at which theory and the body of scientific knowledge are specifically connected in design research. This is associated to communication of research, self-evaluation and distillation of research knowledge from across the field (Glasgow \& Emmons, 2007; Hevner, 2007; Kitchenham et al., 2004). Indicators of health are: 
- Widespread recognition and application of research on scientific knowledge development and the theory building/testing cycle (Horvath, 2016);

- High levels of specific meta-analytical and review based research (Vasconcelos \& Crilly, 2016);

- Consistent and high levels of replication, reporting of negative results, and open access to data (Crilly \& Cardoso, 2017).

\section{Notes}

1. Via Google Scholar accessed October 2017.

\section{References}

Amundson, S. D. (1998). Relationships between theory-driven empirical research in operations management and other disciplines. Journal of Operations Management, 16(4), 341-359.

Araujo, C. S., Benedetto-Neto, H., Campello, A. C., Segre, F. M., \& Wright, I. C. (1996). The utilization of product development methods: A survey of UK industry. Journal of Engineering Design, 7(3), 265-277.

Ball, L. J., Evans, J. St. B. T., Dennis, I., \& Ormerod, T. C. (1997). Problem-solving strategies and expertise in engineering design. Thinking \& Reasoning, 3(4), $247-270$.

Ball, L. J., Onarheim, B., \& Christensen, B. T. (2010). Design requirements, epistemic uncertainty and solution development strategies in software design. Design Studies, 31(6), 567-589.

Ball, L. J., \& Ormerod, T. C. (2000a). Applying ethnography in the analysis and support of expertise in engineering design. Design Studies, 21(4), 403-421.

Ball, L. J., \& Ormerod, T. C. (2000b). Putting ethnography to work: The case for a cognitive ethnography of design. International Journal of Human-Computer Studies, 53(1), 147-168.

Bansal, P., \& Corley, K. (2011). From the Editors: The coming of age for qualitative research. Academy of Management Journal, 54(2), 233-237.

Barab, S., \& Squire, K. (2004). Design-based research: Putting a stake in the ground. The Journal of the Learning Sciences, 13(1), 1-14.

Bedny, G. Z., \& Harris, S. R. (2005). The systemic-structural theory of activity: Applications to the study of human work. Mind, Culture, and Activity, 12(2), $128-147$.

van der Bijl-Brouwer, M., \& Dorst, K. (2017). Advancing the strategic impact of human-centred design. Design Studies, 53(November), 1-23.

Blessing, L. T. M. (2003). What is this thing called design research?. In ICED 03 international conference on engineering design (pp. 9-10). Stockholm.

Blessing, L. T. M., \& Chakrabarti, A. (2009). DRM, a design research methodology. New York: Springer.

Boutron, I., Dutton, S., Ravaud, P., \& Altman, D. G. (2010). Reporting and interpretation of randomised controlled trials with statistically nonsignificant results for primary outcomes. Journal of the American Medical Association, 303(20), 2058-2064.

Brennan, L., Castro, S., Brownson, R. C., Claus, J., \& Orleans, C. T. (2011). Accelerating evidence reviews and broadening evidence standards to identify effective, promising, and emerging policy and environmental strategies for prevention of childhood obesity. Annual Review of Public Health, 32, 199-223. 
Briggs, R. O. (2006). On theory-driven design and deployment of collaboration systems. International Journal of Human-Computer Studies, 64(7), 573-582.

Briggs, R. O., \& Schwabe, G. (2011). On expanding the scope of design science in IS research. In Service-oriented perspectives in design science research: 6th international conference, DESRIST 2011 (pp. 92-106). Berlin Heidelberg: Springer Verlag.

Cagan, J., Dinar, M., Shah, J. J., Leifer, L., Linsey, J., Smith, S. M., et al. (2013). Empirical studies of design thinking: Past, present, future. In DETC '13: ASME 2013 design engineering technical conferences (pp. 1-12). Portland, Oregon, USA.

Carroll, J. M., \& Swatman, P. A. (2000). Structured-case: A methodological framework for building theory in information systems research. European Journal of Information Systems, 9(4), 235-242.

Cash, P., \& Culley, S. (2014). The role of experimental studies in design research. In P. Rodgers, \& J. Yee (Eds.), The Routledge companion to design research (pp. 175-189). New York, NY, USA: Routledge.

Cash, P., Elias, E. W. A., Dekoninck, E., \& Culley, S. J. (2012). Methodological insights from a rigorous small scale design experiment. Design Studies, 33(2), $208-235$.

Cash, P., \& Kreye, M. E. (2017). Uncertainty driven action (UDA) model: A foundation for unifying perspectives on design activity. Design Science, 3(e26), 1-41.

Cash, P., Skec, S., \& Storga, M. (2013). A bibliometric analysis of the DESIGN 2012 conference. In ICED 13 international conference on engineering design. Seoul, South Korea.

Cash, P., \& Snider, C. (2014). Investigating design: A comparison of manifest and latent approaches. Design Studies, 35(5), 441-472.

Cash, P., Stankovic, T., \& Storga, M. (2016a). An introduction to experimental design research. In P. Cash, T. Stanković, \& M. Štorga (Eds.), Experimental design research: Approaches, perspectives, applications (pp. 3-12). Cham: Springer International Publishing.

Cash, P., Stankovic, T., \& Storga, M. (Eds.). (2016b). Experimental design research: Approaches, perspectives, applications. Springer.

Chai, K. H., \& Xiao, X. (2012). Understanding design research: A bibliometric analysis of design studies (1996-2010). Design Studies, 33(1), 24-43.

Clay, R. (2010). More than one way to measure. Monitor on Psychology, 41(8), 52.

Collins, A., Joseph, D., \& Bielaczyc, K. (2004). Design research: Theoretical and methodological issues. The Journal of the Learning Sciences, 13(1), 15-42.

Colquitt, J. A., \& Zapata-Phelan, C. P. (2007). Trends in theory building and theory testing: A five-decade study of the Academy of Management Journal. Academy of Management Journal, 50(6), 1281-1303.

Coughlan, P., \& Mashman, R. (1999). Once is not enough: Repeated exposure to and aesthetic evaluation of an automobile design prototype. Design Studies, 20(6), 553-563.

Crilly, N., \& Cardoso, C. (2017). Where next for research on fixation, inspiration and creativity in design? Findings from an international workshop. Design Studies, 50, 1-38.

Crilly, N., Moultrie, J., \& Clarkson, P. J. (2004). Seeing things: Consumer response to the visual domain in product design. Design Studies, 25(6), $547-577$.

Cross, N. (1993). Science and design methodology: A review. Research in Engineering Design, 5(2), 63-69. 
Cross, N. (1997). Descriptive models of creative design: Application to an example. Design Studies, 18(4), 427-440.

Cross, N. (1999). Design research: A disciplined conversation. Design Issues, $15(2), 5-10$.

Cross, N. (2007). Forty years of design research. Design Studies, 28(1), 1-4.

Cross, N. (2012). Editorial. Design Studies, 33(1), 1-3.

Cross, N. (2017). The history of the design thinking research symposium. In Analysing design thinking: Studies of cross-cultural co-creation (pp. xi-xiv).

Daalhuizen, J. (2014). Method usage in Design: How methods function as mental tools for designers. (PhD Thesis). TU Delft..

Daft, R. L., \& Lengel, R. H. (1986). Organizational information requirements, media richness and structural design. Management Science, 32(5), 554-571.

DerSimonian, R., \& Laird, N. (1986). Meta-analysis in clinical trials. Controlled Clinical Trials, 7(3), 177-188.

Dillon, P. (2006). Creativity, integrativism and a pedagogy of connection. Thinking Skills and Creativity, 1(2), 69-83.

Dong, A. (2005). The latent semantic approach to studying design team communication. Design Studies, 26(5), 445-461.

Dorst, K. (2008). Design research: A revolution-waiting-to-happen. Design Studies, 29(1), 4-11.

Dorst, K., \& Cross, N. (2001). Creativity in the design process: Co-evolution of problem-solution. Design Studies, 22(5), 425-437.

Dubin, R. (1978). Theory building. New York, NY: The Free Press.

Dyba, T., \& Dingsoyr, T. (2008). Empirical studies of agile software development: A systematic review. Information and Software Technology, 50(9-10), $833-859$.

Eisenhardt, K. M. (1989). Building theories from case study research. Academy of Management Review, 14(4), 532-550.

Eisenhardt, K. M., \& Graebner, M. E. (2007). Theory building from cases: Opportunities and challenges. Academy of Management Journal, 50(1), 25-32.

Fanelli, D. (2015). Negative results are disappearing from most disciplines and countries. Scientometrics, 90(3), 891-904.

Fish, J., \& Scrivener, S. A. R. (1990). Amplifying the mind's eye: Sketching and visual cognition. Leonardo, 23(1), 117-126.

Flay, B. R., Biglan, A., Boruch, R. F., Castro, F. G., Gottfredson, D., Kellam, S., et al. (2005). Standards of evidence: Criteria for efficacy, effectiveness and dissemination. Prevention Science, 6(3), 151-175.

Flyvbjerg, B. (2006). Five misunderstandings about case-study research. Qualitative Inquiry, 12(2), 219-245.

Freeman, M., Preissle, J., Roulston, K., \& Pierre, E. A. S. (2007). Standards of evidence in qualitative research: An incitement to discourse. Educational Researcher, 36(1), 25-32.

Friedman, K. (2003). Theory construction in design research: Criteria: Approaches, and methods. Design Studies, 24(6), 507-522.

Fu, K., Cagan, J., \& Kotovsky, K. (2010). Design team convergence: The influence of example solution quality. Journal of Mechanical Design, 132(11), 1-11.

Galle, P. (1999). Design as intentional action: A conceptual analysis. Design Studies, 20(1), 57-81.

Gemser, G., De Bont, C., Hekkert, P., \& Friedman, K. (2012). Quality perceptions of design journals: The design scholars' perspective. Design Studies, $33(1), 4-23$.

George, G., Haas, M. R., \& Pentland, A. (2014). Big data and management. Academy of Management Journal, 57(2), 321-326. 
Gero, J. S. (1990). Design prototypes: A knowledge representation schema for design. AI Magazine, 11(4), 26.

Glasgow, R. E., \& Emmons, K. M. (2007). How can we increase translation of research into practice? Types of evidence needed. Annual Review of Public Health, 28(1), 413-433.

Glass, G. V. (1976). Primary, secondary, and meta-analysis of research. Educational Researcher, 5(10), 3-8.

Goetz, J. P., \& LeCompte, M. D. (1981). Ethnographic research and the problem of data reduction. Anthropology \& Education Quarterly, 12(1), 51-70.

Gonçalves, M., Cardoso, C., \& Badke-Schaub, P. (2016). Inspiration choices that matter: The selection of external stimuli during ideation. Design Science, 2(November), e10.

Gorard, S., \& Cook, T. D. (2007). Where does good evidence come from? International Journal of Research and Method in Education, 30(3), 307-323.

Gorb, P., \& Dumas, A. (1987). Silent design. Design Studies, 8(3), 150-156.

Gottfredson, D. C., Cook, T. D., Gardner, F. E. M., Gorman-Smith, D., Howe, G. W., Sandler, I. N., et al. (2015). Standards of evidence for efficacy, effectiveness, and scale-up research in prevention science: Next generation. Prevention Science, 16(7), 893-926.

Grant, M. J., \& Booth, A. (2009). A typology of reviews: An analysis of 14 review types and associated methodologies. Health Information \& Libraries Journal, 26(2), 91-108.

Gregor, S. (2006). The nature of theory in information systems. MIS Quarterly, 30(3), 611-642.

Gregor, S., \& Jones, D. (2007). The anatomy of a design theory. Journal of the Association for Information Systems, 8(5), 312-336.

Grimes, D. A., \& Schulz, K. F. (2002). An overview of clinical research: The lay of the land. The Lancet, 359(9300), 57-61.

Haidich, A. B. (2010). Meta-analysis in medical research. Hippokratia, 14(Suppl 1), 29-37.

Handfield, R., \& Melnyk, S. A. (1998). The scientific theory-building process: A primer using the case of TQM. Journal of Operations Management, 16(4), $321-339$.

Hanson, W. E., Creswell, J. W., Plano-Clark, V. L., Petska, K. S., \& Creswell, J. D. (2005). Mixed methods research designs in counselling psychology. Journal of Counseling Psychology, 52(2), 224-235.

Hay, L., McTeague, C., Duffy, A., Pidgeon, L., Vuletic, T., \& Grealy, M. (2017). A systematic review of protocol studies on conceptual design cognition. In Design computing and cognition '16 (pp. 135-153). Cham: Springer International Publishing.

Hevner, A. R. (2007). A three cycle view of design science research. Scandinavian Journal of Information Systems, 19(2), 87-92.

Heymann, M. (2009). "Art" or science? Competing claims in the history of engineering design. In S. Christensen, B. Delahousse, \& M. Meganck (Eds.), Engineering in context (pp. 227-244). Aarhus, Denmark: Academica.

Higgins, J. P. T., Green, S., \& Collaboration, C. (2008). Cochrane handbook for systematic reviews of interventions. Chichester, UK: Wiley Online Library.

Hitt, M. A., Beamish, P. W., Jackson, S. E., \& Mathieu, J. E. (2007). Building theoretical and empirical bridges across levels: Multilevel research in management. Academy of Management Journal, 50(6), 1385-1399.

Honig, B., Lampel, J., Siegel, D., \& Drnevich, P. (2017). Special section on ethics in management research: Norms, identity, and community in the 21 st century. The Academy of Management Learning and Education, 16(1), 84-93. 
Horvath, I. (2004). A treatise on order in engineering design research. Research in Engineering Design, 15(3), 155-181.

Horvath, I. (2016). Theory building in experimental design research. In P. Cash, T. Stankovic, \& M. Storga (Eds.), Experimental design research: Approaches, perspectives, applications (pp. 209-231). Springer.

Hultink, E. J., Talke, K., Griffin, A., \& Veldhuizen, E. (2011). Market information processing in new product development: The importance of process interdependency and data quality. IEEE Transactions on Engineering Management, 58(2), 199-211.

Ioannidis, J. (2005). Contradicted and initially stronger effects in highly cited clinical research. Journal of the American Medical Association, 294(2), 218-228.

Johnston, M. V., Sherer, M., \& Whyte, J. (2006). Applying evidence standards to rehabilitation research. American Journal of Physical Medicine \& Rehabilitation, 85(4), 292-309.

Karjalainen, T.-M., \& Snelders, D. (2010). Designing visual recognition for the brand*. Journal of Product Innovation Management, 27(1), 6-22.

Kavakli, M., Scrivener, S. A. R., \& Ball, L. J. (1998). Structure in idea sketching behaviour. Design Studies, 19(4), 485-517.

King, A. M., \& Sivaloganathan, S. (1999). Development of a methodology for concept selection in flexible design strategies. Journal of Engineering Design, 10(4), 329-349.

Kirk, R. E. (2009). Experimental design. London, UK: Sage Publications.

Kitchenham, B., Pearl Brereton, O., Budgen, D., Turner, M., Bailey, J., \& Linkman, S. (2009). Systematic literature reviews in software engineering: A systematic literature review. Information and Software Technology, 51(1), $7-15$.

Kitchenham, B. A., Dyba, T., \& Jorgensen, M. (2004). Evidence-based software engineering. In 26th international conference on software engineering (pp. 273-281).

Kitchenham, B. A., Pfleeger, S. L., Pickard, L. M., Jones, P. W., Hoaglin, D. C., El-Emam, K., et al. (2002). Preliminary guidelines for empirical research in software engineering. IEEE Transactions on Software Engineering, 28(8), $721-734$.

Larsen, K. (2015). Inter-nomological network (INN). Online.

Le Masson, P., Dorst, K., \& Subrahmanian, E. (2013). Design theory: History, state of the art and advancements. Research in Engineering Design, 24(2), $97-103$.

Levin, J. R., \& O’Donnell, A. M. (1999). What to do about educational research's credibility gaps? Issues in Education, 5(2), 177-229.

Liang, A., Sporn, B., Galliers, B., \& Roe, B. (2015). Chartered association of business schools' academic journal guide.

Linsey, J. S., Green, M. G., Murphy, J. T., Wood, K. L., \& Markman, A. B. (2005). An experimental study of group idea generation techniques. In DETC '05: ASME 2005 design engineering technical conferences (pp. 1-14). Long Beach, USA.

Linsey, J. S., Markman, A. B., \& Wood, K. L. (2012). Design by analogy: A study of the WordTree method for problem re-representation. Journal of Mechanical Design, 134(4), 1-12.

Love, T. (2000). Philosophy of design: A meta-theoretical structure for design theory. Design Studies, 21(3), 293-313.

Love, T. (2002). Constructing a coherent cross-disciplinary body of theory about designing and designs: Some philosophical issues. Design Studies, 23(3), $345-361$. 
Maher, M. L., \& Poon, J. (1996). Modeling design exploration as co-evolution. Computer-Aided Civil and Infrastructure Engineering, 11(3), 195-209.

Malhotra, M. K., \& Grover, V. (1998). An assessment of survey research in POM: From constructs to theory. Journal of Operations Management, 16(4), 407-425.

Malterud, K. (2001). Qualitative research: Standards, challenges, and guidelines. The Lancet, 358(9280), 483-488.

Maxwell, S. E., Lau, M. Y., \& Howard, G. S. (2015). Is psychology suffering from a replication crisis? What does "failure to replicate" really mean? American Psychologist, 70(6), 487-498.

McAlpine, H., Cash, P., \& Hicks, B. (2017). The role of logbooks as mediators of engineering design work. Design Studies, 48(January), 1-29.

McMahon, C. (2010). The multiple traditions of design research.

McMahon, C. (2012). Reflections on diversity in design research. Journal of Engineering Design, 23(8), 563-576.

Melnyk, S. A., \& Handfield, R. B. (1998). May you live in interesting times...the emergence of theory-driven empirical research. Journal of Operations Management, 16(4), 311-319.

Meredith, J. (1993). Theory building through conceptual methods. International Journal of Operations \& Production Management, 13(5), 3-11.

Michie, S., Johnston, M., Francis, J., Hardeman, W., \& Eccles, M. (2008). From theory to intervention: Mapping theoretically derived behavioural determinants to behaviour change techniques. Applied Psychology, 57(4), 660-680.

Molina-Azorin, J. F. (2010). The use and added value of mixed methods in management research. Journal of Mixed Methods Research, 5(1), 7-24.

Morrow, S. L. (2007). Qualitative research in counselling psychology. The Counseling Psychologist, 35(2), 209-235.

NCIB. (2015). PubMed. PubMed database.

Neuliep, J. W. (1991). Replication research in the social sciences. Thousand Oaks, CA: Sage.

Nock, M. K., Michel, B. D., \& Photos, V. I. (2007). Single-case research designs. In D. McKay (Ed.), Handbook of research methods in abnormal and clinical psychology (pp. 337-350). Los Angeles: Sage Publications.

Onwuegbuzie, A. J., \& Leech, N. L. (2006). Linking research questions to mixed methods data analysis procedures. Qualitative Report, 11(3), 474-498.

Ozkan, O., \& Dogan, F. (2013). Cognitive strategies of analogical reasoning in design: Differences between expert and novice designers. Design Studies, 34(2), 161-192.

Person, O., Schoormans, J., Snelders, D., \& Karjalainen, T.-M. (2008). Should new products look similar or different? The influence of the market environment on strategic product styling. Design Studies, 29(1), 30-48.

Poldrack, R. A., Kittur, A., Kalar, D., Miller, E., Seppa, C., Gil, Y., et al. (2011). The cognitive atlas: Toward a knowledge foundation for cognitive neuroscience. Frontiers in Neuroinformatics, 5, 17.

Poynard, T., Munteanu, M., Ratziu, V., Benhamou, Y., Di Martino, V., Taieb, J., et al. (2002). Truth survival in clinical research: An evidence-based requiem? Annals of Internal Medicine, 136(12), 888-895.

Redstrom, J. (2006). Towards user design? on the shift from object to user as the subject of design. Design Studies, 27(2), 123-139.

Reich, Y. (2010). My method is better! Research in Engineering Design, 21(3), $137-142$.

Reiser, O. L. (1939). Aristotelian, Galilean and non-Aristotelian modes of thinking. Psychological Review, 46(2), 151-162. 
Reynolds, P. D. (1971). A Primer in theory construction. Indianapolis: BobbsMerrill.

Robinson, M. A. (2010). Work sampling: Methodological advances and new applications. Human Factors and Ergonomics in Manufacturing \& Service Industries, 20(1), 42-60.

Robinson, M. A. (2016). Quantitative research principles and methods for human-focused research in engineering design. In P. Cash, T. Stankovic, \& M. Storga (Eds.), Experimental design research: Approaches, perspectives, applications (pp. 41-64). Springer.

Robinson, H., Segal, J., \& Sharp, H. (2007). Ethnographically-informed empirical studies of software practice. Information and Software Technology, 49(6), $540-551$.

Robson, C., \& McCartan, K. (2011). Real world research (4th ed.). Chichester: Wiley.

Sackett, D. L., Rosenberg, W., Gray, J. A., Haynes, R. B., \& Richardson, W. S. (1996). Evidence based medicine: What it is and what it isn't. British Medical Journal, 312(7023), 71-72.

Sandoval, W. A., \& Bell, P. (2004). Design-based research methods for studying learning in context: Introduction. Educational Psychologist, 39(4), 199-201.

Scandura, T. A., \& Williams, E. A. (2000). Research methodology in management: Current practices, trends, and implications for future research. Academy of Management Journal, 43(6), 1248-1264.

Scrivener, S. A. R., Ball, L. J., \& Tseng, W. (2000). Uncertainty and sketching behaviour. Design Studies, 21(5), 465-481.

Seale, C., \& Silverman, D. (1997). Ensuring rigour in qualitative research. The European Journal of Public Health, 7(4), 379-384.

Shah, S., \& Corley, K. (2006). Building better theory by bridging the quantitative-qualitative divide. Journal of Management Studies, 43(8), 1821-1835.

Sheldon, D. (2004). A review on the relevance of design science in a global product development arena. Journal of Engineering Design, 15(6), 541-550.

Sheldon, D. (2006). Design review 2005/2006: The ever increasing maturity of design research papers and case studies. Journal of Engineering Design, 17(6), $481-486$.

Sio, U. N., Kotovsky, K., \& Cagan, J. (2015). Fixation or inspiration? A metaanalytic review of the role of examples on design processes. Design Studies, 39, 70-99.

Smith, E. R., \& Conrey, F. R. (2007). Agent-based modeling: A new approach for theory building in social psychology. Personality and Social Psychology Review, 11(1), 87-104.

Snow, C. C., \& Thomas, J. B. (2007). Field research methods in strategic management: Contributions to theory building and testing. Journal of Management Studies, 31(4), 457-480.

Sowden, P. T., Pringle, A., \& Gabora, L. (2015). The shifting sands of creative thinking: Connections to dual process theory. Thinking \& Reasoning, 21(1), 40-60.

Sparrowe, R. T., \& Mayer, K. J. (2011). Publishing in AMJ-part 4: Grounding hypotheses. Academy of Management Journal, 54(6), 1098-1102.

Spitas, C. (2011). Analysis of systematic engineering design paradigms in industrial practice: A survey. Journal of Engineering Design, 22(6), 427-445.

Taddio, A., Pain, T., Fassos, F. F., Boon, H., Ilersich, A. L., \& Einarson, T. R. (1994). Quality of nonstructured and structured abstracts of original research articles in the British Medical Journal, the Canadian Medical association Journal and the Journal of the American Medical association. Canadian Medical 
Association Journal: Canadian Medical Association Journal = Journal de l'Association Medicale Canadienne, 150(10), 1611-1615.

Tashakkori, A., \& Teddlie, C. (2008). Foundations of mixed methods research: Integrating quantitative and qualitative approaches in the social and behavioral sciences. Thousand Oaks, CA: Sage.

Tsang, E. W. K., \& Kwan, K. M. (1999). Replication and theory development in organizational science: A critical realist perspective. Academy of Management Review, 24(4), 759-780.

Vasconcelos, L. A., \& Crilly, N. (2016). Inspiration and fixation: Questions, methods, findings, and challenges. Design Studies, 42(C), 1-32.

Vasilev, M. R. (2013). Negative results in european psychology journals. Europe's Journal of Psychology, 9(4), 717-730.

Verganti, R. (2008). Design, meanings, and radical innovation: A metamodel and a research agenda*. Journal of Product Innovation Management, 25(5), 436-456.

Wacker, J. G. (1998). A definition of theory: Research guidelines for different theory-building research methods in operations management. Journal of Operations Management, 16(4), 361-385.

Wacker, J. G. (2008). A conceptual understanding of requirements for theorybuilding research: Guidelines for scientific theory building. Journal of Supply Chain Management, 44(3), 5-15.

Walls, J. G., Widmeyer, G. R., \& El Sawy, O. A. (1992). Building an information system design theory for vigilant EIS. Information Systems Research, 3(1), 36-60.

Wieseler, B., Kerekes, M. F., Vervoelgyi, V., McGauran, N., \& Kaiser, T. (2012). Impact of document type on reporting quality of clinical drug trials: A comparison of registry reports, clinical study reports, and journal publications. BMJ (Clinical Research Ed.), 344(jan03_1), d8141.

Wilkinson, L. (1999). The task force on statistical inference (1999). Statistical methods in psychology journals: Guidelines and explanations. American Psychologist, 54(8), 594-604.

Winter, R. (2008). Design science research in Europe. European Journal of Information Systems, 17(5), 470-475.

Yu, B. Y., Honda, T., Sharqawy, M., \& Yang, M. (2016). Human behavior and domain knowledge in parameter design of complex systems. Design Studies, 45, $1-26$. 